\title{
Rivalidade, parricídio intelectual e invasão de fronteiras na trajetória de Cruz Costa
}

Bruno Bontempi Junior

Resumo: Este artigo aborda relações conflituosas entre intelectuais protagonizadas por João Cruz Costa, catedrático de Filosofia da Universidade de São Paulo. A primeira delas, marcada pela rivalidade entre a Faculdade de Filosofia, Ciências e Letras da Universidade de São Paulo e o Instituto Brasileiro de Filosofia; a segunda, caracterizada pelo "parricídio" que teve lugar no próprio departamento de Filosofia, alimentado pela luta em torno do legado de Jean Maugüé; na terceira, pode-se ver Cruz Costa transitar pelas fronteiras disciplinares que separam os mundos da Filosofia e da História.

Palavras-chave: História das ideias. Intelectuais. Cruz Costa. Universidade de São Paulo.

Tendo iniciado seus estudos superiores na Faculdade de Medicina, mas sem conclúi-los, o paulistano João Cruz Costa (19041978) viu, na fundação da Universidade de São Paulo (1934), a oportunidade de mudar de trajetória e dedicar-se à filosofia. Aluno da

\footnotetext{
* Professor da Faculdade de Educação da Univer-sidade de São Paulo. Endereço eletrônico: bontempi@usp.br
} 
Rivalidade, parricídio intelectual e invasão de fronteiras...

primeira turma da Faculdade de Filosofia, Ciências e Letras (FFCLUSP), tornou-se assistente do catedrático Jean Maugüé, entre 1937 e 1945, doutorou-se na matéria em 1942 e, em 1950, conquistou em concurso público a cátedra de Filosofia, na qual se dedicou por muitos anos à pesquisa e ao ensino da filosofia, tendo seu interesse voltado para a história e "vicissitudes" do "pensamento brasileiro". Personagem emblemático e controverso do ambiente filosófico e acadêmico paulista, para Antonio Candido (1992, p. 167), Cruz Costa teria encarnado

a sucessão harmoniosa de etapas na história da cultura superior brasileira: tendo iniciado a formação filosófica na fase do autodidatismo, completou-a, quando estava amadurecendo, pela aquisição do saber disciplinado.

O suposto caráter harmonioso de sua formação intelectual destoa, porém, do conflituoso e acidentado percurso de Cruz Costa pela universidade e pelo campo da filosofia paulista, cujos momentos críticos são narrados neste artigo. Articulando fontes variadas, como biografias, memórias, depoimentos, documentos institucionais, resenhas, artigos e livros, buscou-se compreender suas "vicissitudes" como diferentes expressões das lutas travadas no campo da produção intelectual ${ }^{1}$ em torno de rivalidades institucionais, sucessão de gerações, relações de poder no interior dos departamentos e questões de fronteira disciplinar ${ }^{2}$.

\section{Rivalidade}

Em Contribuição à História das Idéias no Brasil (1956), Cruz Costa realizou um estudo de história das ideias pautado na recusa à sistematização e ao julgamento do valor filosófico das obras, no reconhecimento das "vicissitudes" nativas na apropriação de ideias importadas e na consideração das fontes e processos pelos quais 
os pensadores brasileiros vieram a conhecê-las. Interessado nas transformações ou deformações sofridas pelas doutrinas ou sistemas de pensamento europeus no Brasil, afirma que este país viveu uma experiência peculiar, pois as condições materiais e espirituais de sua "vida histórica" agiram sobre o pensamento adventício, modificando-o. Para Cruz Costa, as ideias e teorias nascidas na Europa submetem-se sempre, na América, a um estilo próprio, "condicionado pelo próprio devir histórico dos povos, que determina ou que influi na transformação dos sistemas que a inteligência constrói para explicar a vida”. A tarefa do estudioso da história das ideias no Brasil seria examinar as "origens da vida intelectual brasileira para, em seguida, deslindar o significado próprio de cada uma dessas doutrinas ou sistemas", tendo como ponto de partida a "rica trama portuguesa" que a teria marcado com a orientação prática da atividade intelectual e o apego à realidade, elementos que já diferiam o medievo ibérico do restante da Europa (COSTA, 1956).

Boa parte dos acidentes do ulterior percurso intelectual de Cruz Costa parece ter sua origem ou, ao menos, seus primeiros registros nessa obra. Para começar, em Contribuição à História das Ideias no Brasil (1956), Cruz Costa afirma que a história não é feita para restaurar o passado, mas para libertar dele, e que a filosofia é verdadeira se e quando encontra sua adequação à realidade histórica. O caráter político deste "historicismo pragmático" converge para uma orientação política socialista, que se manifesta para além do pensamento puro, no engajamento a essa causa. Em 1945, Cruz Costa subscreveu o programa técnico-eleitoral da Coligação Democrática Radical (1945), frente única à esquerda, que, entre outras propostas radicais, exigia sufrágio universal, direto e secreto; liberdade de agremiação, reunião e imprensa; liberdade sindical e direito de greve; aperfeiçoamento e expansão do alcance das leis trabalhistas; liberdade de consciência e de culto; separação do Estado da Igreja; divórcio; ensino leigo; ensino primário obrigatório e gratuito até os 14 anos; estatização dos bancos e companhias concessionárias de serviços públicos; abolição dos trustes e cartéis; partilha 
Rivalidade, parricídio intelectual e invasão de fronteiras...

da terra; revisão democrática do imposto de renda (CATANI et al., 1998, p. 225-248).

O posicionamento político à esquerda e sua filosofia militante já faziam de Cruz Costa um antípoda de outros intelectuais paulistas ocupados com a filosofia. Trata-se do grupo do integralista Miguel Reale, germinado na Faculdade de Direito da Universidade de São Paulo (FD) e reunido no Instituto Brasileiro de Filosofia (IBF). Além de divergências políticas com esse grupo, havia importantes "diferenças filosóficas", fundadas no dissenso em torno da existência de uma "filosofia nacional", mas tremendamente aguçadas pela rivalidade entre as instituições a que se filiavam, as quais travavam disputa pela legitimidade do exercício da filosofia no panorama cultural paulistano. Os atos de intolerância recíproca, narrados a seguir, devem ser compreendidos à luz desses elementos.

Em suas Memórias, Reale (1986) tece críticas ao tipo de filosofia que teria sido inaugurado com a fundação da FFCL-USP. Desde então, o ensino e o cultivo da filosofia teriam tomado uma "forma acadêmica", que privilegiava os métodos de análise dos clássicos em detrimento da preocupação de formular "um pensamento próprio, como se não nos fosse dado pôr e tentar resolver problemas de ordem universal, a partir de nossas peculiares circunstâncias". Para Reale, o IBF viera à luz para alterar tal quadro de "retração espiritual", ocupando-se de "uma urgente revisão na exegese das obras de nossos 'fillosofantes', palavra com que depreciativamente eram designados os nossos pensadores, nos meios acadêmicos". A menção ao termo "filosofantes", com que Cruz Costa costumava se referir aos pensadores nacionais, define o alvo da crítica de Reale. No IBF, Cruz Costa era tido como um representante da tendência de análise do pensamento filosófico marcada pela adoção de uma "perspectiva ideal" ou de um parâmetro de análise enviesado pela ideologia, pelo qual

só se atribuía importância àqueles autores que, mesmo sem quaisquer méritos de meditação autônoma, estivessem em 
maior ou menor consonância com os pontos de vista ideológicos acolhidos pelo crítico (REALE, 1986, p. 219-226).

Mais do que diversas, as orientações filosóficas e didáticas da FD, reduto original do IBF, e da FFCL-USP, eram opostas. Em seus pontos e momentos de contato, oscilou-se da ironia provocativa a verdadeiros impasses institucionais. Entre os últimos, certamente figura o episódio ocorrido durante o primeiro reitorado de Reale na USP (1949-1950), envolvendo Cruz Costa e os membros do IBF pleiteantes à cadeira de Filosofia. A cadeira em questão foi posta em concurso em 1951, obedecendo ao Decreto 19.851/31, que dispunha que a primeira nomeação de um catedrático seria por dez anos, ao fim dos quais poderia ser reconduzido mediante aprovação em concurso de títulos igual ao prescrito para a primeira nomeação. Cruz Costa, que já a ocupava, era o seu "candidato natural". Quatro membros do IBF, entretanto, inscreveram-se para o concurso, ao que as autoridades da FFCL-USP responderam com a impugnação da inscrição de todos os concorrentes, sob a alegação de não apresentarem em seus currículos o estudo de filosofia (UNIVERSIDADE DE SÃO PAULO, 1952, p. 97-121). Ao lançarem mão de um parecer de Almeida Júnior, no qual se defendia não ser filosofia a filosofia do direito que os candidatos traziam de seus cursos jurídicos, mas apenas uma parte integrante da ciência jurídica, as autoridades da FFCL-USP mostraram ter entendido que a ofensiva do IBF à vaga em concurso representava o seu interesse em tomar posse da cabeça-de-ponte da filosofia acadêmica paulista.

Do outro lado da moeda, o tratamento dispensado a Cruz Costa na Revista Brasileira de Filosofia $(R B F)$, publicação trimestral do instituto presidido por Reale, indica como o IBF lidou com seus antagonistas na filosofia paulista. Sob a capa de juízos cientificamente fundados, surgem nela desavenças pessoais e lutas por espaço institucional e legitimidade do discurso filosófico - ou do discurso sobre a filosofia. Em artigo da RBF, Antônio Paim (1968) celebra a entrada do IBF em seu vigésimo ano de existência, destacando 
Rivalidade, parricídio intelectual e invasão de fronteiras...

dois aspectos marcantes na atuação da entidade: o fato de ter conseguido congregar "todas as tendências filosóficas em nosso meio", feito apenas exequível devido à "ampla liberdade de opinião" assegurada pelo fundador e presidente do instituto, e a atenção consagrada ao pensamento brasileiro. Examinando o expediente da $\mathrm{RBF}$, verifica-se, porém, que a atividade político-ideológica do integralista Miguel Reale fez-se critério, tanto para a escolha dos membros do instituto, como para a seleção dos colaboradores da revista. De fato, as restrições à filosofia de extração marxista no periódico, quando abordada em seus artigos e resenhas, são evidentes. Embora o IBF recomende objetividade aos filósofos na apreciação das doutrinas divergentes, Marx e os marxistas lá recebem tratamento hostil, como nos artigos de Arnóbio Graça (1951, p. 117), que, analisando o marxismo à luz de Jacques Maritain, nele identifica "grandes erros e alguns lampejos de verdade", e de Alexandre Correia (1951, p. 487), para quem, a atitude marxista, "negando à burguesia qualquer possibilidade de evolução positiva", é "inaceitável": "não podemos admitir que a burguesia seja necessariamente reacionária, nem que seu destino seja morrer, desaparecer, esmagada pelo proletariado".

Para o IBF, Cruz Costa era um marxista, com toda a negatividade que tal rótulo comportava. No diagrama filosófico brasileiro, elaborado por Paim em História das idéias filosóficas no Brasil, o catedrático da USP constituiria, ao lado de Leônidas de Rezende, a "manifestação mais expressiva" do marxismo acadêmico, ou seja, a versão positivista que expressava vivamente a permanência do cientificismo oitocentista. De acordo com Paim (1968, p. 485), Cruz Costa pertencia a uma espécie de marxismo acadêmico que "estabeleceu um nível de discussão do marxismo que se tem revelado capaz até mesmo de, por vezes, permear a pregação de representantes dos profissionais da política”.

Embora Paim afirmasse que o IBF sempre se furtara à retaliação pessoal, pois “o plano das idéias é o primado da razão” (1968, p. 90), as alterações de humor nas sucessivas resenhas das obras 
de Cruz Costa ao longo de dezessete anos permitem afirmar que tal postura poucas vezes foi mantida. De 1951 a 1956, ou seja, nos primeiros vinte fascículos da $\mathrm{RBF}$, o nome de Cruz Costa não havia sido sequer mencionado. $\mathrm{O}$ único artigo de sua autoria publicado integra uma seção especial, de quatro páginas, publicada em 1960 e intitulada "Filosofia na América". O escrito foi retirado dos Anais do Congresso Interamericano de Filosofia, em Washington (EUA), em 1957. As demais menções a Cruz Costa irão aparecer mais tarde, em resenhas de seus livros publicadas na seção "Bibliografia".

A primeira delas é de 1957 e versa sobre O positivismo na República, de 1956. Assinada por Luís Washington de Vita, ressalta o mérito do autor em partir de um "ponto de vista sociologista" para desfazer certos mitos a respeito das circunstâncias de assimilação e adaptação do positivismo no Brasil, tais como a de que os positivistas teriam contribuído para a ciência brasileira e a de que deles se tenha haurido boas contribuições no campo das ideias políticas. Para Vita (1957, p. 361-362), outro mérito do trabalho do "ilustre catedrático da Universidade de São Paulo" seria o de demonstrar que "é possível o livre exame sem difamação...".

Em 1958, Esbozo de una história de las ideas en el Brasil, resumo em espanhol de Contribuição à história das ideias no Brasil, lançado em 1957, foi resenhado em conjunto com A Filosofia no Brasil, de Hélio Jaguaribe (1957); Momentos decisivos e olvidados do pensamento brasileiro (1958), de Miguel Reale, e Ideologia e desenvolvimento nacional (1956), de Álvaro Vieira Pinto. Na resenha, Vita (1958, p. 385386) argumenta que os trabalhos têm em comum a preocupação em aferir a filosofia brasileira, realizando uma incipiente "filosofia da filosofia no Brasil", e reconhece que a confluência dos trabalhos é curiosa, tendo em vista a conciliação, no plano das ideias, de "estudiosos pessoalmente incompatíveis". Segundo Vita,

Cruz Costa, Miguel Reale e o grupo do ISEB travam um paradoxal 'contrato filosófico', dando a razão da nossa falta 
Rivalidade, parricídio intelectual e invasão de fronteiras...

de originalidade especulativa, explicando-a e compreendendo-a à base situacional do processo histórico do país.

Em 1959, em homenagem prestada pela Companhia Editora Nacional ao primeiro centenário da morte do fundador do positivismo, deu-se a reedição da obra Augusto Comte e as origens do positivismo. A RBF consagra-lhe, então, uma resenha - ou um discorrer sobre o positivismo, doutrina de que Vita discorda veementemente ilustrada por citações do livro. Vita reitera a afirmação com que finalizara o comentário de 1957, de que Cruz Costa "é o único dentre os nossos filosofantes capaz de fazer uma síntese compreensiva do legado comteano 'sine ira et studio"3"' (VITA, 1959, p. 274). Essa tolerância para com Cruz Costa, evidentemente fomentada pela interpretação convergente dos excessos do positivismo em terras brasileiras, começa a se alterar em 1960. No volume 10, Vita (1960, p. 584-585) dedica resenha a Panorama da história da filosofia no Brasil, publicado pelo catedrático naquele ano. Sobrevêm as primeiras críticas, ainda que polidas pela retórica:

A fidelidade do professor Cruz Costa à filosofia brasileira, a ela dedicando-lhe toda sua vida de estudos e todos seus livros, com exceção de sua tese de doutorado, apesar de afirmar que "de fato, temos simplesmente glosado o pensamento europeu e não contribuímos até hoje para o patrimônio da Filosofia com nenhuma criação", não obstante ver o pensador brasileiro de todos os tempos não como "filósofo", mas como "filosofante" (...), essa fidelidade - dizíamos - se reveste, por vezes, de um dramatismo que nem seu espírito irônico consegue abalar (VITA, 1960, p. 584-585).

Estão aqui presentes os pontos nodais da ofensa que as premissas de Cruz Costa representavam para os integrantes do IBF. Não só eles se consideravam filósofos, descendentes de uma linha de pensamento que tivera início com Tobias Barreto no século XIX, como se esmeravam em ressaltar a importância, senão para a 
filosofia, ao menos para a formação da nação brasileira, de personagens como Silvio Romero, Farias Brito e Pereira Barreto. Podese acrescentar, a título de conjectura, que também o proverbial "espírito irônico" de Cruz Costa desagradasse à sisuda filosofia ibeefeana. Todavia, apesar das divergências, a resenha ainda é pouco contundente. Por isso mesmo, no número seguinte, outra resenha do mesmo livro é publicada, agora por Reale (1961, p. 123), que justifica a inusitada repetição pela premência de "alguns esclarecimentos".

$\mathrm{Na}$ resenha de Reale, Cruz Costa surge como "historiador das ideias no Brasil", cujos méritos residiriam no cuidado com as fontes e na "correlação íntima" que logra estabelecer entre as ideias e as conjunturas sociais e históricas, "dispensando especial atenção à infraestrutura econômica". Como todo historiador - prossegue —, Cruz Costa paga "tributo a preferências pessoais", manifestas em dois preconceitos recorrentes: seu "horror à Metafísica" e sua prevenção contra os "bacharéis que andaram vagueando, como diletantes, pelo mundo da Filosofia, mas que, bem ou mal, atuaram decisivamente no processo de nossas ideias". Reale passa, então, a enumerar as indagações que, considerando os "objetivos estritos" da nota, não cabem ser nela respondidas: se Cruz Costa dá, coerentemente, maior destaque às doutrinas que "de fato influíram em nossa forma de vida ou no plano de nossas experiências concretas", se consagra o espaço que seria devido a Tobias Barreto e Farias Brito em Contribuição à história das idéias no Brasil. O erro que Reale dispõe-se a comentar é o desprezo do autor, fundado na redução do "concreto" ao "empírico", pelo "significado dos seguidores de Santo Tomás nos quadrantes da cultura brasileira":

Para Cruz Costa (...) basta que um trabalho seja escolástico ou apresente "laivos de metafísica" para ser, desde logo, posto de lado, com um gesto de desconfiança, ou mesmo de desprezo, mais compreensível na obra de certos neo-positivistas que não merecem, bem o sei, nem o seu, nem o meu entusiasmo... (REALE, 1961, p. 124). 
Rivalidade, parricídio intelectual e invasão de fronteiras...

A partir desse ponto, a resenha toma ares de briga pessoal: Reale passa a relatar um recente conflito entre ambos. Segundo o comentarista, Cruz Costa teria revidado "numa zanga mais própria de menino" à crítica, desprovida de "aleivosia ou injúria", que lhe havia feito em uma conferência, por ter desconsiderado a importância de textos de escolásticos brasileiros em Contribuição à história das idéias no Brasil. Cruz Costa, além de ironizar o comentário, teria adicionado um "quinau professoral", chamando a sua atenção para uma imprecisão cometida naquela conferência, com relação à história luso-brasileira. Pedindo a cumplicidade do leitor, Reale atinge o antagonista, fazendo uso de suas próprias palavras:

Como vê o leitor, a lição afoita da história fica reduzida às proporções de uma carinhosa contribuição à revisão de um lapso evidente, como deve acontecer nesta nossa modesta comunidade de homens ocupados com as mais altas tarefas do espírito. (...) Compartilho de muitas opiniões de Cruz Costa sobre o estudo da Filosofia no Brasil, mas nenhum de seus ensinamentos me parece mais oportuno do que o expendido sobre o valor do convívio filosófico quando fundado "no hábito da humildade intelectual que é incompatível com a vaidade tola do brilhareco professoral" (REALE, 1961, p. 126).

Vita encarregar-se-ia, novamente, de uma resenha de um livro de Cruz Costa. Desta vez, trata-se da segunda edição de Contribuição à história das idéias no Brasil, datada de $1967^{5}$. Onze anos depois de seu aparecimento, a "abordagem unilateral" da filosofia brasileira continuava a despertar a impaciência dos ibeefeanos. Ainda que afirmasse prezar "o método rigoroso e erudito" das pesquisas de Cruz Costa, o tom da crítica de Vita, anteriormente diplomático, é ácido:

'Torna-se impossível um conhecimento teórico que não atenda às condições históricas'. É esta posição doutrinária que levará Cruz Costa a adotar, metodologicamente, o binário do evolver político e econômico como condicionador da 
filosofia no Brasil, defluindo daí uma estranha história das idéias com predominância daquela (história) e mera presença destas (idéias) que só adquirem alguma significação quando engajadas (VITA, 1967, p. 234).

Por fim, em 1968, no já mencionado artigo comemorativo do vigésimo aniversário do IBF, Cruz Costa é apresentado como contraponto à "tendência compreensiva na apreciação do pensamento filosófico nacional", inaugurada e representada pelo IBF - e associado aos "sistemáticos", a quem sempre fizera questão de criticar e marcar as diferenças. Segundo Paim (1968, p. 91),

(...) a tradição que nos foi legada nessa matéria é a de Sílvio Romero, logo seguida por Leonel Franca e Cruz Costa. Todos os três limitam-se a valorizar os seus próprios momentos ou as suas perspectivas. (...) Quanto ao professor Cruz Costa, limita-se a exaltar as idéias com que simpatiza e que, suponho, resumem-se a uma versão positivista do marxismo. Falta-lhes qualquer sentido das circunstâncias históricas em que militaram as grandes figuras de nossa meditação filosófica, entre as quais se incluem, sem dúvida, os dois primeiros, galeria que possivelmente será integrada por Cruz Costa, quando a distância permitir às novas gerações que emitam um julgamento isento do resultado de sua erudição (PAIM, 1968, p. 91).

Os membros do IBF expressam no tratamento dado ao rival as modalidades combinadas de divergências filosóficas e políticas, pontilhadas de vaidade pessoal dos interlocutores e vazadas pela luta institucional entre FFCL-USP e IBF pelo controle da "palavra filosófica", ou seja, a luta pela legitimação das respectivas expressões filosóficas, pela ocupação do espaço reservado à filosofia no mundo cultural paulista e, na confluência, o prosseguimento dos choques que marcavam, desde a fundação da USP, os embates entre os representantes das antigas e novas instituições de formação da elite intelectual do estado. 
Rivalidade, parricídio intelectual e invasão de fronteiras...

\section{Parricídio $^{6}$}

Jean Maugüé, jovem professor contratado para iniciar os cursos da Cadeira de Filosofia, inaugurados em 1934 por Etienne Borne, deixou seus pressupostos, estratégias e objetivos para o ensino de filosofia expressos no documento "O ensino da Filosofia: suas diretrizes", identificado por Arantes (1994) como alicerce do programa crítico da filosofia na FFCL-USP. Convidado a fixar as condições do ensino de filosofia na nova faculdade, Maugüé as resumiu na fórmula "A filosofia não se ensina. Ensina-se a filosofar", que significaria, de acordo com Arantes (1994, p. 64), "que em vão se procurará um corpo de verdades já constituídas, que sejam objetivamente transmissíveis e em face das quais o talento do professor representaria apenas o papel de mero acidente".

Com base nessa ideia e tendo em vista elaborar as "condições de possibilidade do discernimento no trato com os textos e as questões filosóficas" na FFCL-USP, Maugüé alinhou em suas diretrizes "definições de princípio" a "conselhos práticos e preceitos escolares". A argumentação funda-se na peculiaridade da filosofia entre as matérias do pensamento, que consiste em constituir, ela mesma, o esforço para encontrar a origem comum de todo conhecimento assimilável pelas ciências objetivas. Assim sendo, o seu estudo não deveria preceder o das outras ciências, posto ser necessário que a inteligência primeiramente se exerça e produza resultados, para que então possa "voltar-se sobre si mesma". Por ser um esforço de reflexão sobre conhecimentos e atividades não criados por ela, a filosofia exige uma "cultura vasta e precisa" e seu ensino não pode se antecipar à aquisição de cultura. A segunda condição para o ensino da filosofia seria compreender que ela "vive no presente", não sendo "corajosamente filósofo senão aquele que cedo ou tarde expressa o seu pensamento acerca das questões atuais". Para ser mais seguramente contemporâneo, contudo, o ensino da filosofia deverá ser primordialmente histórico - eis a terceira condição. No caso do Brasil de então, cujos principais "traços ideológicos" 
identificados pelo mestre francês eram o gosto pela novidade e o utilitarismo do interesse pelas correntes filosóficas, a história da filosofia se impunha como a própria base do ensino, uma vez que a ela cabia dar ao país condições de "filttrar a sua imigração espiritual" (UNIVERSIDADE DE SÃO PAULO, 1935, p. 25-35).

Apoiado nos testemunhos de antigos alunos ilustres, Antonio Candido e Gilda de Mello e Souza, Arantes (1994, p. 68) sustenta que Maugüé concretizava brilhantemente o programa de ensino traçado, lecionando em um estilo fluente, que combinava o "vasto repertório teórico muito bem armado" ao "improviso inspirado" e impressionava pela facilidade com que os mais diversos assuntos do presente - arte, política, relações pessoais - eram abordados da perspectiva filosófica. Nas palavras de Candido (1992, p. 236), justamente por não ser um "filósofo acadêmico" (Maugüé fora normalista e professor de liceu) e por não acreditar muito nas instituições universitárias, o professor corporificava a própria condição da faculdade que, até meados dos anos 1940, teria tido "menos uma função específica, de formar especialistas em Filosofia, do que a função genérica de criar uma atmosfera favorável ao espírito crítico e à reflexão sobre a realidade social e cultural".

Quando veio a Segunda Grande Guerra, Maugüé e outros professores estrangeiros tiveram de retornar a seus países de origem. A cadeira de história de filosofía foi então interinamente ocupada pelo assistente Lívio Teixeira e mantida intocada, na expectativa do retorno do regente. Quando se soube que o regente não voltaria, em 1948, Martial Guéroult foi contratado para o seu lugar. O relatório da cadeira no Anuário da FFCL-SP declara a continuidade das antigas diretrizes, ao afirmar que a

orientação [de Maugüe], sua maneira de encarar os problemas filosóficos, marcam até hoje seus discípulos, especialmente os que tiveram o privilégio de ser seus continuadores no ensino da Filosofia (UNIVERSIDADE DE SÃO PAULO, 1952, p. 463). 
Rivalidade, parricídio intelectual e invasão de fronteiras...

O mesmo deu-se na cadeira de filosofia, já regida por Cruz Costa, antes mesmo da partida de Maugüé. Como se lê no relatório do Anuário,

(...) entendeu o professor [Cruz Costa] (...) que, no Brasil, onde a cultura filosófica sempre se manifestou por uma tendência unilateral, que era aconselhável dirigir o ensino da Filosofia, num sentido que acentuasse a importancia histórica dos sistemas e dos problemas filosóficos. Aliás, sobre este aspecto, nada mais fez do que seguir a orientação que lhe imprimira o Sr. Prof. Jean Maugüé (UNIVERSIDADE DE SÃO PAULO, 1952, p. 463).

Em depoimento, Cruz Costa (1975, p. 90) afirmaria, mais tarde, que Lívio Teixeira e ele não procuraram imprimir outras diretrizes de ensino após a saída de Maugüé:

Nós, sob certo aspecto, éramos um pouco como o Getúlio [Vargas], que dizia: 'Deixa como está para ver como fica'. O Departamento ia se diferenciando natural e lentamente, tendo em conta o pessoal docente de que dispúnhamos e o heterogêneo pessoal discente que afluía à Faculdade.

A memória do departamento, entretanto, mostra-se distante da ideia de ter havido um prosseguimento "natural" das diretrizes de Maugüé por seus sucessores imediatos 7 . O depoimento de Bento Prado Jr. (2000, p. 203), que nele ingressou em 1956, indica os motivos da quebra de continuidade entre a sua época e os primeiros tempos:

Os meus primeiros quatro anos como estudante de filosofia foram anos de "vacas magras" no nosso Departamento. Por uma série de coincidências o meu curso foi provavelmente o menos privilegiado. Foi justamente um período vazio da presença de professores visitantes. Quando entrei, em 1956, o Lefort tinha voltado para a França e Lebrun só veio para 
o Brasil em 1960. Nesses quatro anos o Granger fez algumas visitas, uma série de conferências, mas é diferente de ter um professor full time. Além disso, dos jovens professores, o Giannotti viajou para a França pela primeira vez em 1958 e ficou dois anos fora, e o Ruy Fausto deu apenas um semestre de aula. O velho Cruz Costa, por sua vez, teve uma briga com o então governador Jânio Quadros, foi punido e, por um certo período, não deu aula. Quer dizer, o corpo docente se reduziu consideravelmente (PRADO JR., 2000, p. 203).

$\mathrm{Na}$ cadeira de filosofia, o então assistente Laerte Ramos de Carvalho parecia ser o "candidato natural" à cátedra e à tarefa de levar adiante os interesses e objetos da filosofia de Cruz Costa, por sua vez, assumidos como um prosseguimento de Maugüé. Porém, antes mesmo da chegada da nova geração ao departamento de filosofia, Ramos de Carvalho se retirara para a cadeira de história e filosofia da educação, abdicando assim do legado de seu mestre. José Arthur Giannotti lembra que a saída do assistente foi providencial, porque abriu caminho para a ambientação de Giles Granger, que até então sofria “a hostilidade velada dos ensaístas e do pessoal de Laerte". Além disso, ofereceu espaço para que um grupo diverso, politicamente "tomado pelo nacionalismo, e filosoficamente mergulhado na História da Filosofia e na Epistemologia" ganhasse espaço. Ainda de acordo com Giannotti (1974, p. 28), desse modo,

o Departamento ficou sem a geração intermediária, liderada por Antonio Candido, Florestan Fernandes etc., o que nos permitiu [aos jovens do departamento] ascender rapidamente a posições de liderança.

Interrompia-se, assim, mediante oposição interna nascida no departamento, o traçado da filosofia de Cruz Costa.

A crítica feita em 1968 por Bento Prado Jr. à Contribuição à história das idéias no Brasil expressa como síntese a miríade de críticas 
Rivalidade, parricídio intelectual e invasão de fronteiras...

informais e dispersas que os estudantes faziam aos modos de seu professor Cruz Costa. Embora, anos mais tarde, Bento Prado Jr. tenha publicado sua autocrítica e apontado os erros e insuficiências de sua leitura "estrutural-gauchista" (PRADO JR., 1986, p. 103), a verdade é que, com ela, como atestou Arantes (1994), completou-se o "eclipse" de Cruz Costa no departamento de filosofia. Resumidamente, as críticas dirigiam-se principalmente aos exacerbados "historicismo" e "psicologismo" com que Cruz Costa procurava abordar o pensamento brasileiro.

Na obra de Cruz Costa (...) tudo se passa como se se tratasse de projetar a história futura através da investigação do passado (...) uma volta à infância que você vai buscar na memória (...). Daí, inclusive, o interesse pela história das ideias no Brasil: vamos estudar como é que se fez a filosofia no Brasil desde sempre para que daqui para frente se possa fazer filosofia em continuidade com esse legado que embora seja ruim é tão bom, isto é, para que daqui para frente nós possamos ser marxistas (PRADO JR., 1986, p. 118-119).

A sensação de descontinuidade (a ausência da "geração intermediária") e o esforço crítico da geração "radical" fizeram com que a memória da filosofia uspiana destoasse das narrativas idílicas de continuidade entre as gerações, presentes nos registros de outras cadeiras e departamentos da FFCL-USP (UNIVERSIDADE DE SÃO PAULO, 1994), e que as contendas em torno de sua história e polêmica memória sobre Cruz Costa fossem disso os sintomas mais notáveis. Em outras narrativas do nascimento e desenvolvimento das cadeiras e departamentos da FFCL, personagens como Cruz Costa teriam sido preservados em memória como "elos" entre os mestres estrangeiros e a terceira geração de professores da faculdade. Entretanto, os representantes das novas gerações do departamento de Filosofia optaram pelo parricídio, mais tarde confessado (PRADO JR., 1986; ARANTES, 1994). 


\section{Invasão de fronteiras}

Na interpretação de Arantes (1994), não só a obra de Cruz Costa era tributária de antigas formas de ensaísmo nacionalista, alheias ao universo de interesses da mocidade universitária, como a própria escolha da história das ideias no Brasil como objeto de estudo teria sido rejeitada pelas novas gerações, uma vez que soava como disparate procurar manifestações do pensamento nacional à altura de constituírem objeto da filosofia. Em outras cadeiras e departamentos, todavia, a experiência dos primeiros anos parecia estimular na nova geração a inclinação oposta: o estímulo dado por professores como Roger Bastide e Pierre Monbeig para o estudo da realidade brasileira encontrava sentido nas condições peculiares tão ao gosto da sociologia e da geografia acadêmicas. Uma visada positiva para o assunto brasileiro era, por isso, despertada pelos próprios estrangeiros. Segundo Antonio Candido e Decio de Almeida Prado (apud PONTES, 1998, p. 31), Bastide insistia para que seus alunos visitassem, por exemplo, as igrejas coloniais dos arredores de São Paulo, que ele, embora tendo chegado recentemente ao Brasil, já conhecia.

No caso da história, a diferenciação entre história geral da civilização e história da civilização brasileira gerava na FFCL-USP um desdobramento inusitado da questão do interesse sobre o assunto nacional. Porque os fundadores da USP não ousaram convidar um estrangeiro para ensinar história do Brasil, a cadeira de história da civilização brasileira foi ocupada inicialmente por Afonso Taunay e Alfredo Ellis Júnior, membros do Instituto Histórico e Geográfico de São Paulo. Se os franceses introduziram a orientação metodológica da historiografia dos Annales, na cadeira de história da civilização brasileira, Ellis Jr. e Taunay a neutralizaram, ao menos até o ingresso de Sérgio Buarque de Holanda, que, com Visão do Paraíso (1958), apontava para os estudos de cultura e de mentalidades (UNIVERSIDADE DE SÃO PAULO, 1994). Por sua vez, 
Rivalidade, parricídio intelectual e invasão de fronteiras...

na cadeira de história geral da civilização, regida por um francês, e na de história da civilização americana, regida por um norte-americano, o interesse era "universal", e não "nacional", o que impedia a manifestação de certas vocações, como lembra Fernando Novaes,

(...) o professor Eduardo França disse-me que desejou fazer sua tese sobre História do Brasil, mas não pôde, porque era assistente da cadeira de História Moderna e Contemporânea. Assim, sua primeira tese foi sobre o poder real e as origens do absolutismo em Portugal. Isto porque, de certa forma, queria estar próximo da História do Brasil (...). O segundo trabalho do professor França foi também sobre Portugal, focalizando a época da Restauração. Eu mesmo fiz a minha tese sobre o Brasil Colonial, encontrando um tema que articulasse Portugal e Brasil, dado que não se podia escrever um trabalho sobre o Brasil numa cadeira de História Moderna e Contemporânea (NOVAES, 1994, p. 165, grifos meus).

De acordo com Carlos Guilherme Mota, uma importante contribuição ao campo dos estudos em história das ideias no Brasil teria vindo de fora do departamento de História da FFCL. Trata-se de Contribuição à história das idéias no Brasil, que teria sido uma das mais marcantes obras da primeira geração acadêmica, interessada em "libertar-se seja da perspectiva mitológica, bandeirista, tipificadora dos Institutos Históricos, seja da orientação factualista ingênua, marcada entre nós pelo positivismo científico de Langlois-Seignobos". Para Mota (1980, p. 34-35), em Cruz Costa, o "pensamento é sempre o produto sutil da atividade de um povo", tipo de proposta que ultrapassava os limites da história événementielle, característica, segundo ele, do período anterior. Não tendo comovido as novas gerações do departamento de Filosofia, no departamento de História, Cruz Costa ajudou a ferir de morte a história "bandeirista". Por um desses paradoxos da história intelectual, a mesma personagem, ultrapassada entre filósofos, mostrou-se avançada entre historiadores. 
Em 1968, no prefácio de Brasil em Perspectiva, Cruz Costa explica "mais um aspecto da razão do convite" para escrevê-lo, feito pelo organizador Carlos Guilherme Mota. Ao fazê-lo, localiza no tempo a sua guinada disciplinar: calculando os anos a partir do que relata, verifica-se que o crescimento de seu interesse pela História data de fins da década de 1940:

\begin{abstract}
A certa altura de minha vida, há quase trinta anos, embora eu houvesse sempre dedicado grande interesse à nossa história, este interesse era um hobby, pois o meu campo de trabalho limitava-se ao estudo e ao ensino da filosofia. Deu-se então uma ligeira mudança no meu destino. O que até aí havia sido apenas um hobby, transformou-se em quase angustiosa e justificada preocupação. Foi a essa altura que comecei a tentar imaginar as curiosas vicissitudes das ideias no Brasil (COSTA, 1987, p. 7).
\end{abstract}

Com efeito, em Contribuição à história das idéias no Brasil (1956, p. 21), apresentam-se referências que indicam que os liames entre filosofia e história vinham sendo feitos dominantemente pela segunda disciplina. Por isso mesmo, adivinhava as críticas futuras:

Dir-se-á, porém, que este trabalho é trabalho de historiador. Efetivamente. É mister, porém, não esquecer que este historiador deve seguir os infinitos meandros da Geitesgeschichte dos ensaístas alemães, ou os caminhos mais sutis que, no rico e pujante pensamento de L. Febvre, constituem o estudo das sensibilidades, isto é, do estudo dos níveis intelectuais e culturais. É necessário ainda que o historiador das idéias aplique aos seus estudos os processos de análise e os métodos de um Marcel Mauss, atento sempre ao bombardeio cósmico das civilizações pelas civilizações vizinhas... Além disso, é mister que possa, do próprio interior da apaixonante e inquietadora história pátria, reconstituir o trabalho, muitas vezes doloroso, da formação de nossa terra, dos dramas 
Rivalidade, parricídio intelectual e invasão de fronteiras...

de consciência que constituem a aventura da sua história espiritual. É preciso ainda que se procure apreender, nessa movediça história nacional, o sentido dessas aventuras e integrá-las nos seus quadros de vida, do mesmo modo que se coloca um rio entre duas margens (COSTA, 1956, p. 21).

A referência de Cruz Costa ao programa de Febvre, definido pelo filósofo brasileiro como "o estudo das sensibilidades, isto é, o estudo dos níveis intelectuais e culturais", e à sociologia de Mauss, remetem aos fundadores da escola dos Annales e à "história das mentalidades". Entretanto, a menção a Febvre traduz-se em sua obra em pouco mais do que a concordância quanto à dupla recusa da história política factual e da história intelectual da primeira metade do século XX, que isolava as ideias ou os sistemas de pensamento das condições de sua produção. Embora inspirado em Febvre, Cruz Costa não chega a operar com os instrumentos de análise elaborados pelo francês - fundamentalmente, o conceito de utensilagem mental [outillage mental] - com o qual pretendia reconstituir os sentimentos e as sensibilidades próprios aos homens de cada época.

Além de mostrar-se atualizada com relação às vogas historiográficas alemãs e francesas, a obra de Cruz Costa inova com a incorporação efetiva das decisivas interpretações da realidade brasileira, trazidas de fora da Universidade pelos livros de Caio Prado Jr., Sérgio Buarque de Holanda e Gilberto Freyre. Com efeito, Cruz Costa afirmou mais tarde que suas preocupações com a reescrita da história brasileira foram inspiradas pelos autores de Raízes do Brasil e Casa Grande \& Senzala (COSTA, 1975, p. 91).

Por sua vez, a ideia de que toda história implica uma filosofia faz combinar em seu método as diretrizes de Maugüé, para quem o estudo da filosofia é inelutavelmente histórico, e o materialismo histórico de Caio Prado Jr., presente em Formação do Brasil Contemporâneo (1942), obra sobre a qual Cruz Costa sustentou toda a argumentação histórica de sua tese de cátedra. Os seus contatos com as teses de Marx e com o marxismo precedem o ingresso dessas referências 
na universidade - para não dizer que precedem a própria USP. Ele, que nunca militou no Partido Comunista, entrou em contato com o pensamento de Marx aos 18 anos em Paris, nos anos 1920, momento em que o marxismo tinha ainda pouca repercussão nos meios universitários ${ }^{8}$. Considerando que as interpretações de inspiração marxista só passaram a constituir "referencial importante" no departamento de História nas teses de doutoramento defendidas a partir de 1951, Cruz Costa foi o primeiro, dentre os primeiros formados pela FFCL-USP, a apoiar-se no materialismo histórico para pensar o Brasil.

É possível identificar nos primeiros trabalhos de Cruz Costa referências diretas a obras de Marx e Engels, além de afirmações da existência de uma relação dialética entre ideias e base material e, derivadamente, do "poder espiritual" como manifestação da dominação material de uma classe sobre a outra (COSTA, 1946, p. 15-18). Quanto aos fundamentos da história marxista, Cruz Costa (1956, p. 23) invoca Charles Morazé para fundamentar que não se pode

abstrair a cultura filosófica do complexo condicionalismo histórico e a essência humana também depende, embora não lhe seja exclusivamente submetida, das forças produtivas, de relações sociais que as gerações encontram como dado fundamental.

Da historiografia marxista, aparece com destaque em toda a sua obra a atenção dada à investigação de processos sociais e econômicos amplos e complexos e, mais como promessa do que como tema tratado, o papel das massas na história.

Ao levar às últimas consequências o postulado de Maugüé, que assentava nas estreitas ligações entre filosofia e história, terminou por extrapolar as fronteiras disciplinares da primeira para alcançar as da segunda. Buscava na história - "o laboratório do filósofo" - as referências e exemplos úteis ao seu programa de 
Rivalidade, parricídio intelectual e invasão de fronteiras...

investigação, ainda que titubeando pelos caminhos escuros pelos quais passaria o relâmpago modernizador dos Annales. A revisão de Bento Prado Jr. (1986, p. 119-124) sobre os escritos de 1968, em que condenava a filosofia historicista e psicologista de Cruz Costa, indica que a chave para a interpretação de sua obra poderia não estar mesmo na filosofia, mas na história:

Eu concordo com quase todas essas críticas que eu fiz, mas o que eu ignorava na época - e que me fazia julgar mal ou julgar incorretamente ou parcialmente a obra de Cruz Costa - é no fundo a própria noção de história (...) eu tenho a impressão que neste momento, ao fazer esta verificação, ao mesmo tempo a gente confirma as intuições básicas de Cruz Costa; a filosofia brasileira não pode ser pensada independentemente da história social do país, e, no fundo, isso só é possível com a idade, para quem é filósofo de formação. Para quem é filósofo de formação, são necessários $40 \mathrm{ou}$ 50 anos de vida para descobrir que o pensamento tem alguma coisa que ver com a sociedade. Esta intuição básica de Cruz Costa - formulada na sua generalidade - pode parecer pobre, mas na tradição da historiografia, ela não o é de fato (PRADO JR., 1986, p. 119-124).

\section{Considerações finais}

Engajado à esquerda, irônico e pouco inclinado a pagar tributos aos "filósofos nacionais", Cruz Costa não teve a simpatia dos filósofos do IBF; inclinado ao estudo histórico das vicissitudes das ideias europeias no Brasil, não encontrou no departamento de Filosofia da FFCL-USP um canteiro em que pudesse fazer florescer o seu interesse e produzir ramificações. Na configuração acadêmica da História, uma estranha bipartição o constrangeu: na cadeira de história da civilização brasileira não havia espaço para novidades 
teóricas e metodológicas alienígenas, como as com que flertava; na cadeira de história geral da civilização, já tocada pelos temas e abordagens dos Annales, ainda não se escrevia sobre temas brasileiros. Finalmente, o seu marxismo algo prematuro não tinha firme ancoragem no meio acadêmico. As disputas lhe foram desfavoráveis; os meios, hostis. A memória não lhe concedeu o legado dos heróis. A trajetória de Cruz Costa, cumprida na transição entre o diletantismo das antigas gerações intelectuais e a especialização do mundo das disciplinas acadêmicas, terminou por expressar a desarmonia das lutas no interior do campo intelectual.

Rivalry, intellectual parricide and boundaries invasion in the life of Cruz Costa Abstract: This article deals with conflicting relations among intellectuals, having João Cruz Costa as the leading figure, Philosophy professor at Universidade de São Paulo. The first one, featured by competition between Faculdade de Filosofia, Ciências e Letras da Universidade de São Paulo and the Instituto Brasileiro de Filosofia; the second one, featured by "parricide" in the very Departamento de Filosofia, nurtured by the struggle for Jean Maugüés legacy; and in the third situation, we can see Cruz Costa crossing boundaries between Philosophy and History.

Keywords: History of ideas. Intellectuals. Cruz Costa. University of São Paulo.

\section{Notas:}

${ }^{1}$ Como mediação entre as produções culturais e a posição dos produtores no espaço social, o campo de produção cultural é um espaço da estrutura social no qual "está em jogo um tipo particular de alvos sociais, interesses que podem ser absolutamente desinteressantes do ponto de vista do que está em jogo no mundo exterior" (BOURDIEU, 1990, p. 115). Nele, empenham-se agentes sociais que lançam mão de estratégias regidas pela lógica da prática, do aprendizado e das apostas no sentido do jogo, cujo objetivo é acumular capital simbólico, forma "de que se revestem as diferentes espécies de capital (econômico e cultural), quando são percebidas, reconhecidas como legítimas" (idem, p. 154). No campo intelectual, o interesse obedece a lógicas que correspondem a sua economia como lugar de produção de "sensos comuns, lugares comuns, sistemas de tópicos irredutíveis uns aos outros", o que transforma a própria "verdade" em jogo de lutas. Cabe, pois, como pretende este artigo, determinar empiricamente as condições sociais da produção desse interesse, além de seu conteúdo específico. 
2 A opção por esta abordagem apoia-se em Lepenies (1983), para quem a história das disciplinas não deve tratar cada modalidade do conhecimento como um todo unificado e autossuficiente, abstraído do conjunto maior formado pela cultura. $\mathrm{O}$ autor sugere que, para uma boa compreensão da economia interna de um campo de saber, deve-se privilegiar a busca por restaurar os dinâmicos e múltiplos "processos de domesticação e de peregrinação" que fazem da história de cada disciplina a história de uma rede de relações interdisciplinares, sejam elas de aliança, emulação, imitação ou desprezo com relação a suas contemporâneas.

${ }^{3}$ Expressão latina, criada pelo jurista e historiador romano Tácito (55-120 d.C) para expressar a imparcialidade na exposição dos fatos. Traduz-se por "sem ódio e sem preconceito".

" O termo "filósofo", na Revista Brasileira de Filosofia, é empregado de bom grado aos que se dedicam à "atividade espiritual" entendida como filosófica, mas nem sempre adere ao especialista em Filosofia, personagem que aparece com o advento dos cursos superiores de Filosofia. Cruz Costa, filósofo formado pela FFCL, é citado preferencialmente na $R B F$ como "filosofante" (quando experimenta o amargo de seu próprio remédio), "ilustre catedrático", "professor" e "historiador das ideias". O emprego cuidadoso da palavra demonstra o quanto foi difícil o assentamento de uma cultura de especialistas em um meio historicamente diletante.

${ }^{5}$ Convém observar que a primeira edição dessa obra jamais havia merecido resenha, embora tivesse sido recebida pela revista no ano mesmo de sua publicação, em 1956. Para que se tenha uma ideia da particular atitude de rejeição diante dessa obra, basta verificar que o livro $O$ positivismo na República fora anunciado como recebido no volume VII, fascículo II, e comentado já no número seguinte.

"Utilizo o termo "parricídio" em analogia com a imagem criada por Sigmund Freud, em Totem e Tabu (1912-1913), para formular a hipótese sobre o surgimento da dupla proibição (da agressividade dirigida ao pai e da sexualidade dirigida à mãe) que teria fundado a sociedade humana. Na imagem do "banquete totêmico" os irmãos oprimidos do clã, vestidos como o totem (animal que substitui simbolicamente o pai primevo), matam-no cruelmente e o devoram cru. Depois de consumado o ato, o morto é pranteado e a culpa que se instala entre os irmãos os leva a renegar a sua ação, proibindo o assassínio do totem e renunciando ao desfrute das mulheres que $o$ ato fez libertar de seu jugo tirano (FREUD, s.d., p. 534-560; GOLDGRUB, 1989, p. 39-42). Na narrativa que empreendo ocorre a morte simbólica de Cruz Costa, que substituía o "pai primevo" Maugüé, e inaugura-se o domínio da nova geração do departamento. Mais tarde, essa "morte" é pranteada; Prado Jr. faz a autocrítica e Arantes reata Cruz Costa a Maugüé. Longe de pretender uma "psicanálise" dos sujeitos e eventos aqui narrados, quis apenas criar uma chave de leitura para este caso atípico de "transmissão de herança" em uma disciplina acadêmica.

${ }^{7}$ Rigorosamente, as cadeiras da FFLC só foram organizadas em departamentos em 1963. Neste artigo, optou-se por usar a denominação "departamento" para os 
diferentes conjuntos formados pelas cadeiras de Filosofia, História e Sociologia, mesmo quando referidos a épocas anteriores à oficialização regimental. Tal opção justifica-se tanto por simplificar a exposição, como por reproduzir mais fielmente a usança dos contemporâneos.

${ }^{8}$ De acordo com (NETO, 2002), Cruz Costa viajou à Europa em 1923, a fim de frequentar o curso preparatório aos exames da Faculdade de Medicina. Em Paris, seguiu cursos de filosofia na Sorbonne, com André Lalande e Leon Brunschvicg, e cursos com Pierre Janet e George Dumas, respectivamente, no Collége de France e no Asilo Sainte-Anne.

\section{Referências}

ARANTES, Paulo Eduardo. Um departamento francês no ultramar. estudos sobre a formação da cultura filosófica uspiana. Rio de Janeiro: Paz \& Terra, 1994.

BOURDIEU, Pierre. Coisas ditas. Tradução de Cássia R. da Silveira e Denise Moreno Pegorim. São Paulo: Brasiliense, 1990.

CANDIDO, Antonio. Brigada ligeira e outros escritos. São Paulo: UNESP, 1992.

CATANI, Afrânio et al. Florestan ou o sentido das coisas. São Paulo: Boitempo: Maria Antonia, 1998.

CORREIA, Alexandre Augusto de C. Marxismo e filosofia burguesa. Revista Brasileira de Filosofia. São Paulo, v.1, f.4, 1951, p. 483-489.

COSTA, João Cruz. O Pensamento brasileiro. Boletim da Faculdade de Filosofia, Ciências e Letras, n. 68. São Paulo: Editora da Universidade de São Paulo, 1946.

. Contribuição à História das Ideias no Brasil. Rio de Janeiro: José Olympio, 1956.

. Entrevista. Sobre o trabalho teórico. Trans/form/ ação, Assis-SP, 1975, p. $87-94$.

Prefácio. In: MOTA, Carlos Guilherme (Org.). Brasilem perspectiva. 16. ed. Rio de Janeiro: Bertrand Brasil, 1987, p. 7-9.

FREUD, Sigmund. Totem e tabu. In: Obras completas de Sigmund Freud. Tradução de Elias Davidovich et alii. Rio de Janeiro: Delta, s.d. (vol. VII).

GRAÇA, Arnóbio. Humanismo ocidental. Revista Brasileira de Filosofia. São Paulo, v.1, f.5, 1951, p.117.

GIANNOT'TI, José Arthur. Entrevista. Sobre o trabalho teórico. Trans/form/ ação, Assis-SP, n. 1, 1974, p. 25-36.

Anos 90, Porto Alegre, v. 16, n. 29, p. 155-181, jul. 2009 
Rivalidade, parricídio intelectual e invasão de fronteiras...

GOLDGRUB, Franklin. O complexo de Édipo. São Paulo: Ática, 1989.

LEPENIES, Wolf. Contribuition à une histoire des raportes entre la sociologie et la philosophie. Actes de la recherche en Sciences Sociales, v. 47-48, 1983, p. 37-44.

MOTA, Carlos Guilherme. Ideologia da cultura brasileira (1933-1974). 4. ed. São Paulo: Ática, 1980.

NETO, Pedro Leão da Costa. João Cruz Costa. In: FÁVERO, M.L.A; BRITTO, J.M. (Orgs). Dicionário de educadores no Brasil. Da colônia aos dias atuais. 2. ed. aum. Rio de Janeiro: Editora UFRJ/MEC-Inep-Comped, 2002, p. 530-536.

NOVAES, Fernando. Braudel e a "Missão Francesa". Estudos Avançados. São Paulo, v. 8, n. 22, 1994, p. 161-166.

REALE, Miguel. Panorama da história da filosofia no Brasil. Revista Brasileira de Filosofia. São Paulo, v.11, f.41, 1961, p.123-124 (Resenha). . Memórias. v. 1. São Paulo: Saraiva, 1986.

PAIM, Antônio. O Instituto Brasileiro de Filosofia. Revista Brasileira de Filosofia, São Paulo: v.18, f.69, 1968, p. 90-93.

. História das idéias filosóficas no Brasil. São Paulo: Convívio, 1984.

PONTES, Heloísa. Destinos mistos: os críticos do Grupo Clima em São Paulo (194068). São Paulo: Cia. das Letras, 1998.

PRADO Jr., Bento. Cruz Costa e a história das ideias no Brasil. In: MORAES, Reginaldo, ANTUNES, Ricardo e FERRANTE, Vera B. (Orgs.). Inteligência Brasileira. São Paulo: Brasiliense, 1986, p. 101-124.

. Entrevista. In: REGO, José Márcio e NOBRE, Marcos (Orgs.). Conversas com filósofos. São Paulo: 34, 2000, p. 199-226.

VITA, Luís W. O positivismo na República. Revista Brasileira de Filosofia. São Paulo, v. 8, f. 2, 1957, p. 360-362. (Resenha).

. Esbozo de una historia de las ideas en el Brasil, de Cruz Costa; A Filosofia no Brasil, de Hélio Jaguaribe; Momentos decisivos e olvidados do pensamento brasileiro, de Miguel Reale; Ideologia e desenvolvimento, de Álvaro Vieira Pinto. Revista Brasileira de Filosofia. São Paulo, v. 8, f. 3, 1958, p. 385-386. (Resenha).

. Augusto Comte e as origens do positivismo. Revista Brasileira de Filosofia. São Paulo: v. 9, f. 2, 1959, p. 274-276. (Resenha).

Panorama da história da filosofia no Brasil. Revista Brasileira de Filosofia. São Paulo, v. 10, f. 4, 1960, p. 584-586. (Resenha).

Anos 90, Porto Alegre, v. 16, n. 29, p. 155-181, jul. 2009 
. Contribuição à história das ideias no Brasil. Revista Brasileira de Filosofia, São Paulo: v. 18, f. 67, 1967, p. 233-236. (Resenha do livro de Cruz Costa).

UNIVERSIDADE DE SÃO PAULO. FACULDADE DE FILOSOFIA, CIÊNCIAS E LETRAS. Programa de 1935. São Paulo: Imprensa Oficial, 1935.

UNIVERSIDADE DE SÃO PAULO. FACULDADE DE FILOSOFIA, CIÊNCIAS E LETRAS. Anuário da Faculdade de Filosofia, Ciências e Letras da Universidade de São Paulo (1950). São Paulo: Seção de Publicações da USP, 1952.

UNIVERSIDADE DE SÃO PAULO. FACULDADE DE FILOSOFIA, CIÊNCIAS E LETRAS. Anuário da Faculdade de Filosofia, Ciências e Letras da Universidade de São Paulo (1939-1949). V.1. São Paulo: Seção de Publicações da USP, 1935

UNIVERSIDADE DE SÃO PAULO. Estudos Avançados. São Paulo, v. 8, n. 22, 1994.

Recebido em: 02/04/2009

Aprovado em: 22/05/2009 